\title{
O DIREITO À CIDADE: DA TRANSCENDÊNCIA À IMANÊNCIA. UMA RELAÇÃO DE CONFRONTO ENTRE CIDADE E NATUREZA
}

\section{THE RIGHT TO THE CITY: FROM TRANSCENDENCE TO IMMANENCE. A CONFRONTATION BETWEEN CITY AND NATURE}

\author{
Valéria do Carmo Ramos ${ }^{1}$ \\ Universidade Federal Fluminense, Brasil \\ Paula Cristina Pereira ${ }^{2}$ \\ Universidade do Porto, Portugal
}

\begin{abstract}
Resumo: Partindo da ideia de direito à cidade de Henri Lefebvre, pretendemos perspetivála de modo a identificar alguns dos problemas que a geraram e a evidenciar como persistem na atualidade. Num segundo momento, procuraremos equacionar a ideia de direito à cidade numa articulação entre transcendência e imanência, tendo como propósito problematizar a impreterível realidade contemporânea, a do Antropoceno; e sugerir, como estratégia, a afirmação de uma outra variante da ética da responsabilidade. Finalmente, na senda de Baruch Spinoza, procuraremos compreender em que sentido a vida exige, hoje, uma composição, uma relação, essencialmente outra, entre natureza e cidade.
\end{abstract}

Palavras-chave: Imanência $\cdot$ Natureza $\cdot$ Pensamento-Corpo $\cdot$ Direito $\cdot$ Cidade

Abstract: Based on Henri Lefebvre's idea of the right to the city, we intend to identify some of the problems that generated this notion and to highlight how they still persist today. We will also attempt to equate the idea of the right to the city located between transcendence and immanence, addressing contemporary reality in its most unavoidable dimension, that of the Anthropocene. We intend furthermore to suggest the affirmation of another variant of the ethics of responsibility as a potential strategy. Finally, in line with Baruch Spinoza, we will explore to what extent life requires today a composition, an essentially other relationship between nature and city.

Keywords: Immanence $\cdot$ Nature $\cdot$ Thought-Body $\cdot$ Law $\cdot$ City

Enviado:07/09/2021. Aceptado:07/12/2021

\footnotetext{
${ }^{1}$ Valéria do Carmo Ramos é Doutora em Filosofia pela Universidade Federal do Rio de Janeiro - RJ/ Brasil; é Professora Titular na Universidade Federal Fluminense, RJ/Brasil; CNPq-Brasil.

${ }^{2}$ Paula Cristina Pereira é Professora Associada do Departamento de Filosofia da Faculdade de Letras da Universidade do Porto (Portugal), Diretora do Programa Doutoral em Filosofia e Investigadora Principal do RG Philosophy \& Public Space do Instituto de Filosofia (UI\&D/FIL/00502). E-mail: paulacristinap@sapo.pt
} 


\section{A IDEIA DE DIREITO À CIDADE: PERSPETIVAS HISTÓRICAS}

Neste artigo, ${ }^{3}$ o entendimento de direito à cidade será perspetivado a partir da obra Le Droit à la Ville, do filósofo Henri Lefebvre, historicamente datada nos anos de 1960, numa Paris que experimentava, a um só tempo, transformações sociais e urbanísticas.

A relevância do pensamento de Lefebvre ancora-se hoje, do nosso ponto de vista, na necessária afirmação de uma noção contemporânea de tempo histórico. $\mathrm{Na}$ realidade, o objetivo, aqui, é remeter para a apreensão da história de um processo; tempo histórico que -com Safatle (2019) - ao invés de guardar "uma repetição da exemplaridade" é, de modo necessário, um tempo que é processualidade marcada pela tensão do não realizável: "tempo que se acelera, se distende, para; mas que se projeta para a frente de algo que não foi visto". Um tempo, ainda com Safatle, que inscreve um outro conceito de História: que, a um só tempo, recupera os acontecimentos passados, mas também é capaz de transformar esses próprios acontecimentos e lançá-los em projeções de um processo futuro, pela tensão do não realizável. Ou seja: a História como um tempo que, permanentemente, se defronta com o inesperado, o imprevisível, numa operação que, por consequência, não apenas fratura um sistema explicativo, mas de maneira simultânea acaba por impelir ao acontecido, de modo retroativo, uma nova e outra ordenação. Uma plasticidade que, exatamente por isso, transfigura de modo radical e estruturante a própria noção de experiência social (Safatle, 2019).

Assim, com o mesmo filósofo, a partir deste vértice histórico, o de uma processualidade contínua e plástica, não cabe falar em inscrição plena e absoluta, já que todo acontecido poderá ser transfigurado pelas forças de um presente que incitam, afetam e pressionam.

E são exatamente as forças que, na atualidade, neste início do século XXI, constituem e pressionam o nosso presente, aquelas que nos impõem a recolocar e a enfrentar o tema-problema do Direito à Cidade. Neste sentido, a obra de Henri Lefebvre é tomada, aqui, como um campo problemático, uma composição conceptual, de pendor prático e concreto, em tensão, cuja força é capaz de contribuir para a compreensão deste nosso mundo.

O interesse, portanto, é a apropriação da referida obra, nas suas dimensões atual e virtual, para dela extrair alguns dos problemas que a engendraram e que continuam a exprimir a sua potência pujante.

Ainda hoje é a relação entre cidade e modo de produção a imbricação, o vértice que se impõe como imprescindível face à necessidade contemporânea

\footnotetext{
${ }^{3}$ Esta publicação enquadra-se nas atividades do Instituto de Filosofia (UI\&D/FIL/00502) da Faculdade de Letras da Universidade do Porto.
} 
de compreender a realidade urbana. E está exatamente aí a base genética para compreender a transição de uma revolução urbana para uma revolução do espaço (cf. Pereira, 2018). O que se exprime na própria voz de Lefebvre: "não há dúvida que cada modo de produção 'produziu' (não como uma coisa qualquer, mas como uma obra privilegiada) um tipo de cidade" (2008b [1970], pp. 31-32).

$\mathrm{Se}$, por um lado, poder-se-ia dizer que se trata de uma realidade urbana, efeito de uma sequência de agudas e surpreendentes transformações, que efetivamente funciona como o signo de uma grande "revolução urbana"; por outro, a assunção deste ponto de vista, segundo Lefebvre, jamais nos fará prescindir de lançar-nos a enfrentar importantes problemas acerca da fórmula "a cidade, o urbano e o espaço" (Pereira, 2018, p. 24).

Mas, se a "era urbana", atual, diz-se numa extensão generalizada, alcançando o próprio limite planetário, cujos efeitos atingem os longínquos cantos do planeta, inclusive a atmosfera e os oceanos, uma problematização parece permanecer: poder-se-ia justapor a essa era urbana uma outra era, a de um novo e outro espaço? (Pereira, 2018):

"Tal passagem revela que o autor, ainda reconhecendo o caráter planetário do urbano e da urbanização, parece ter percebido que ambos não foram capazes de produzir um novo espaço e uma nova sociedade; pelo contrário, as problemáticas existentes até então foram alçadas a um patamar inteiramente novo, sendo reproduzidas com outra envergadura: segregação social e espacial, fragmentação, periferização, todos agora em escala planetária, já que o capitalismo se estendeu ao espaço inteiro, produzindo-o e o transformando numa mercadoria" (...) (Pereira, 2018, p. 27).

Ora, a partir daí, talvez já se possa entrever uma íntima relação entre vida quotidiana, cidade, urbano e espaço; onde urbano e espaço, de modo necessário, se ligam de modo muito estreito. Ou seja: "falar de uma revolução do espaço é ao mesmo tempo falar de uma revolução urbana, que englobaria também o direito à cidade e uma revolução da vida cotidiana" (Pereira, 2018, p. 31). Neste sentido:

“a transfiguração (...) espacial da 'era urbana', não se efetivou, não foi produzida, tendo persistido, agora mais amplamente, o 'espaço abstrato' do neocapitalismo. Assim, presenciamos, nesses termos, uma 'revolução urbana' - no sentido de uma ampliação à escala do planeta do processo urbano, isto é, um processo real em que a problemática urbana assume a sua condição mundial - sem uma 'revolução do espaço' - no sentido de uma outra sociedade e espaço, que ainda permanece virtual". (Pereira, 2018, p. 27)

Analisando a relação entre construção social do espaço urbano e sociedade capitalista, Lefebvre expõe um problema indicado aqui inicialmente: o que caberia às práticas teóricas frente àquilo que constituiria o mais intrínseco à sociedade urbana? 
De modo claro e preciso, a resposta do autor é contundente e vai desdobrarse em duas direções: a imposição de que as práticas teóricas reconfigurem, simultaneamente, as formas, funções e estruturas da cidade - em suas dimensões económicas, políticas, culturais, etc. - mas também recomponham as necessidades sociais referidas à própria natureza das sociedades urbanas que, do ponto de vista afirmado, desviam-se daquelas características da sociedade de consumo, as necessidades individuais.

Apesar de Lefebvre reconhecer que as necessidades sociais se inscrevem em fundamentos antropológicos e que compreenderiam desde "a segurança e a abertura (...), a organização do trabalho e a do jogo (...), a unidade e diferença, até ao isolamento e encontro (...), a previsibilidade e imprevisibilidade" (2001, p. 105), ele acaba por demarcar outros dois tipos de necessidades inerentes ao ser humano: por um lado, a de ver, ouvir, de tocar, de degustar e, por outro, de compor essas perceções num "mundo" possível. No entanto, face a essas necessidades demarcadas, ele irá enfatizar outras, de natureza específica, já que não se subjugam aos equipamentos comerciais e culturais que são, em diferentes escalas, consideradas pelos urbanistas. Tratam-se das necessidades de uma atividade criadora, de construção de uma obra - desde que, segundo o autor, esta não seja reduzida a produtos e bens materiais.

Por consequência, o que se desdobra daí é que, ao elencar essas necessidades urbanas específicas, o sentido alcançado é aquele que anuncia o quanto tais necessidades humanas se apartariam das ideias de espaço físico, valor de troca - tão determinante para o capitalismo - e das dimensões de desmedida e de atual. Neste sentido, Lefebvre é claro ao interrogar:

"[a]s necessidades urbanas específicas não seriam necessidades de lugares qualificados, lugares de simultaneidade de encontro, lugares onde a troca não seria tomada pelo valor de troca, pelo comércio e pelo lucro? Não seria a necessidade de um tempo desses encontros, dessas trocas?" (Lefebvre, 2001, p. 106).

Mas qual seria, exatamente, sob o ponto de vista de Lefebvre, o sentido desatado nesse enunciado? Ora, de modo irrefutável, a afirmação de tal enunciado coloca-nos a interrogação: qual seria a adequada e a necessária ciência analítica da cidade?

Posicionando-se, de maneira radical e crítica, contra a construção do espaço urbano numa modalidade capitalista, Lefebvre irá afirmar de modo preciso que, na época, uma necessária ciência analítica da cidade ainda estava em vias de se delinear. E que avançar com o sentido desse delinear teria forçosamente a ver com a realidade urbana e com a práxis, que são sempre processuais, já que naquele momento histórico havia, com efeito, a superação das ideologias e das práticas que obstaculizavam o saber e a ação. Vale a pena evocar a própria imanência da voz de Lefebvre: 
“A teoria que se poderia legitimar chamar de 'urbanismo' que se reuniria às significações da velha prática chamada 'habitar' (isto é, o humano), que acrescentaria a esses fatos parciais uma teoria geral dos espaços-tempos urbanos, que indicaria uma nova prática decorrente dessa elaboração, este urbanismo existe virtualmente. Só pode ser concebido enquanto implicação prática de uma teoria completa da cidade e do urbano, que supera as cisões e separações atuais". (Lefebvre, 2001, p. 111)

O que se desdobra daí é que, na perspetiva de Lefebvre, configurar aquela ciência da cidade implicaria admitir duas realidades: por um lado, a de que o objeto dessas ciências é necessariamente virtual - o passado, o presente e a condição de realidade para a construção do possível, não se bifurcam; e, por outro, de modo trágico, a total falência de um certo humanismo clássico, afirmando que aquelas ciências não poderiam desenvencilhar-se da "desmedida" e de criar "alguma coisa" à "altura do universo" (Lefebvre, 2001, p. 107).

$\mathrm{Na}$ realidade, o que parece estar em jogo, na perspetiva do autor, é a afirmação contundente de que todas as condições de realidade para a construção de um possível estão dadas e que, a um só tempo, este abrir-se-ia para o da sociedade urbana e do humano como obra, "uma sociedade que seria obra e não produto" (Lefebvre, 2001, p. 107).

Ora, admite aquelas duas realidades para evocar a composição de outros problemas. Tais problemas seriam, segundo Lefebvre, então, o de interrogar-se, de modo efetivo, para onde seria necessário tendermos. E o que caberia a nós nessa operação?

Reforçando, de modo radical, a sua crítica ao humanismo clássico, a resposta de Lefebvre é sustentada na direção das construções de nova práxis e de um outro homem, o homem da sociedade urbana. No entanto, estabelece algumas condições para que não se possa desviar do projeto e implementá-lo: destituir os mitos que ameaçam essa vontade, destruindo as ideologias que desviam esse projeto e as estratégias que afastam esse trajeto (Lefebvre, 2001, p. 108).

Mas o que caberia a nós nessa operação? - importa, ainda, trazer à cena.

Ainda sob os efeitos desses problemas, Lefebvre operará uma aguda resposta que já deixa entrever a potência de sua argumentação crítica.

Se, por um lado, o "nós" funciona como um signo que diz dos intelectuais em diálogo na prática de uma ciência analítica da cidade - portanto, todos os que se interessam por esses problemas -, por outro, estará ao serviço de uma crítica virulenta aos intelectuais interessados, especialmente aos arquitetos. Nenhum desses intelectuais - urbanistas, arquitectos, designer, sociólogos, filósofos, etc. - é capaz de criar relações sociais. No máximo, contribuem para a formulação de alguma tendência. Nesse sentido, portanto, poderiam "limpar o caminho (...), inventariar a 
experiência (...). Mas, de modo inexorável, jamais irão instituir as próprias relações sociais" (Lefebvre, 2001, p. 109).

É, pois, neste cenário que interessa a este trabalho, na atualidade e virtualidade dos enunciados de Lefebvre, trazer à tona a urgente necessidade de nos contagiar com as tensões do seu campo problemático e sublinhar o olhar dos próprios intelectuais e os seus instrumentos para problematizar a grave realidade contemporânea, a do Antropoceno.

Jamais, na história da humanidade, o fenómeno da urbanização alcançou semelhante centralidade como uma potente questão social e humana - aqui, até mesmo, incluindo alguns de seus trepidantes efeitos: “a segregação, a pobreza, os chamados problemas ambientais, o imobiliário, entre outros" (Pereira, 2018, p. 27).

Portanto, em realidade, é incontestável que o século XXI:

“Aprofunda as tendências na direção da construção de uma nova relação espaçotemporal com a hegemonia de novos setores econômicos de realização do capital, iluminando o papel do capital financeiro na reprodução da cidade, inserindo-a de forma mais objetiva, no processo de valorização do capital, através do imobiliário; o que permitiu a extensão da propriedade privada do solo urbano, revelando estratégias imobiliárias, profundamente vinculadas à reprodução do capital - através da indústria da construção civil, e, mais recentemente, com o desenvolvimento dos fundos imobiliários - como estratégia da reprodução do capital financeiro". (Carlos, 2020, s/p)

Ora, dito de modo diferente: o que se desenrola daí é que o projeto de Lefebvre que hoje, inclusive, se prolonga na produção de muitos autores como, por exemplo, David Harvey, Edward Soja, além de alguns mais novos como Lukasz Stanek e Christian Schmid (cf. Pereira, 2018) - alcança uma aguda atualidade no século XXI, como um corpo de pensamento prático e concreto capaz de compreender os movimentos, paradoxos e contradições deste nosso mundo, na exata medida em que a cidade é tornada o lugar da realização humana na produção da vida e o quotidiano torna-se essencial para a reprodução das relações de produção, deixando patentear que, ao capital, é necessário que a produção da vida se inscreva na própria produção do espaço, de modo que ele, capital, possa reproduzirse neste próprio espaço (cf. Souza, 2019). Isto é: “a cidade se transforma em mercadoria escancarando o processo contraditório da produção do espaço tornado valor de troca como momento importante do processo de valorização do capital" (Lefebvre, 2008b (1970), pp. 211-212).

Deste ponto de vista, por consequência, não seria inadequado dizer que tanto a crise urbana que experimentamos hoje, que recoloca na cena contemporânea a necessidade aguda de um Direito à Cidade - agora, em outra constelação -, quanto o Antropoceno, enquanto índice do estágio da civilização contemporânea, em última 
instância, exprimiriam e compartilhariam, nas suas bases, de um mesmo problema ou mesma força motriz: de que maneira o capitalismo ocupa e produz o espaço, de modo, a um só tempo, reproduzir-se nele próprio?

\section{O Antropoceno e as Cidades}

A Terra tem passado, ao longo de seus 4,5 biliões de anos, por profundas transformações que se estenderam por longínquos intervalos de tempo, que respeitam a diferentes "eras geológicas". Cada uma delas deixou as suas impressões singulares, uma espécie de "assinatura" na crosta terrestre e na constituição da biodiversidade do planeta. Por exemplo, segundo alguns pesquisadores,${ }^{4}$ foi a era Cenozóica, a "era da vida recente", iniciada em torno de 60 milhões de anos atrás, aquela que configurou o planeta na forma em que o conhecemos hoje: diferentes continentes e oceanos e o aparecimento dos humanos. No entanto, hoje está em curso algo de inédito, com impactos inelutáveis não apenas para as ciências naturais, mas para todos os domínios de saber; em especial, para o próprio campo filosófico: o Antropoceno, uma nova era geológica. Estado de coisa nomeado, inicialmente, pelo biólogo Stoermer, na década dos anos 80. E reafirmado por Paul J. Crutzen, Prémio Nobel de Química em 1995, numa conferência científica no ano 2000 que, na época, o caracterizou como: "human dominance of biological, chemical and geological processes on Earth - is already an undeniable reality" (cf. Oliveira S. B., 2018). Por conseguinte, se, por um lado, pode dizer-se que se trata de uma problematização longe de estar consensualmente concluída junto às ciências naturais, uma vez que há controvérsias - por exemplo, acerca do marco histórico que deflagra essa nova era -, por outro, parece irrefutável a tendência construída no sentido da compreensão científica de que se trata de uma grave, preocupante e perturbadora transformação, jamais testemunhada pelas humanidades até então.

Mas o que significa, exatamente, na perspetiva das ciências naturais, a afirmação de tal enunciado? Parece, com efeito, remeter para a irredutibilidade de um agudo deslocamento que se traduz num surpreendente estado de coisas: os humanos, que constituíram uma força biológica na superfície da Terra, deslocamse e tornam-se, agora, uma força geológica, como uma força determinante, por exemplo, no funcionamento de nosso sistema climático. Sob a perspetiva das ciências naturais, mostra a investigadora Sônia de Oliveira, já haveria sinais identificados, efetivamente, que levariam ao reconhecimento de uma nova era geológica (cf. Oliveira S. B., 2018).

\footnotetext{
${ }^{4}$ Neste sentido, poderíamos citar os professores e pesquisadores Ricardo Abramovay, sociólogo, e Wagner Costa Ribeiro, geógrafo, ambos vinculados à Universidade de São Paulo (USP-Brasil).
} 
Mas quais seriam, de facto, os marcos irrefutáveis que expressariam a ação antrópica como uma força crescente e determinante na dinâmica e funcionamento da Natureza?

Ainda na linha da mesma investigadora poder-se-ia afirmar que, do ponto de vista das ciências naturais, haveria alguns contundentes e surpreendentes marcadores que exprimiriam, de modo irrefutável, a crescente presença das atividades humanas no mundo natural, afetando, sobremaneira, os processos geológicos. As suas pesquisas mostram que esses indicadores crescem de modo expressivo, convergindo para a data de 1950, como um possível início para a era do Antropoceno. Éramos na Terra um bilião ao iniciar o século XIX, dois biliões em 1930, quatro biliões em 1974 e sete biliões hoje; é, pois, claramente em 1950 que o crescimento populacional se torna mais expressivo (cf. Oliveira S. B., 2018).

Outro marcador, ainda segundo Sônia de Oliveira, diz respeito ao consumo de energia doméstica, cuja curva de crescimento torna-se paralela à do crescimento populacional. Tal consumo está intimamente ligado ao consumo de combustíveis fósseis que vão determinando mudanças muito relevantes na composição dos gases efeito estufa, na atmosfera (cf. Oliveira S. B., 2018).

Outra mudança marcante, diz ainda a mesma investigadora, refere-se à presença de materiais diferentes, isto é, tecnofósseis - fósseis fabricados pela ação humana. Os principais seriam o alumínio metálico, advindo a partir da fabricação de latas de cerveja. Segundo Sônia de Oliveira, embora o alumínio seja abundante na crosta terrestre de modo natural, só a partir da fabricação das latas de cerveja ele aparece combinado com o oxigénio, o alumínio metálico. Também o plástico e o cemento, transportados pelos fluxos dos rios, alcançam as bacias de sedimentação e, assim, tornam-se constituintes das futuras rochas sedimentares.

Pode-se ainda referir a extinção elevada de algumas espécies de animais, também a partir do século XX; na interferência humana no ciclo do fósforo, a partir das atividades das práticas de mineração, nas rochas fosfatinas; ou do hidrogénio criado nos fertilizantes, utilizados na produção dos alimentos, devido ao aumento da população. E, além disso, o ciclo do carbono. Desde 1950, a emissão de CO2 dos combustíveis fósseis tem aumentado expressivamente - especialmente petróleo e gás, contribuindo em $90 \%$. No entanto, há ainda as barragens de rios, por exemplo nos Estados Unidos, e as queimadas como modo de uso da terra, que contribuem com $10 \%$ das emissões de CO2. Além, claro, dos testes nucleares, a partir da $2^{\mathrm{a}}$ Guerra Mundial (cf. Oliveira S. B., 2018).

Ora, o que se desprende daí, ainda segundo a mesma autora, é que as ciências naturais têm diante de si, em especial a Geologia, todas as condições de reconhecimento do Antropoceno, como uma nova era geológica. 


\section{Do Direito À Cidade: DA Transcendência À ImanênCia}

Se, por um lado, parece irrefutável que, frente a esse estado de coisas tão disruptivo - o Antropoceno -, o próprio conceito de direito à cidade concebido por Lefebvre fraturase e desenvolve-se noutra direção; por outro, não há como negar que há uma dimensão virtual da sua obra que diz de um campo problemático em variação contínua, que já aponta para a necessidade de outros humanismos, outros modos de entender a cidade e o direito a ela, capazes de esboçar respostas eficazes àquele estado de coisas. Uma virtualidade capaz de fomentar a emergência de algo inédito, ou seja, a invenção de outros e complexos problemas. Quais sejam: que necessidades engendrariam o direito à cidade hoje? Restringir-se-iam às necessidades humanas? Qual seria a melhor variante de cidade para se viver num mundo como o nosso, globalizado, conturbado e violento, com doenças incomuns, a exigir que se crie uma radical proximidade entre políticas públicas e ciências? Um mundo com um profundo desdém a algumas das viscerais dimensões da vida, para as quais não expressa qualquer acuidade para apreendê-las de modo efetivo especialmente em relação às diferenças e às singularidades constitutivas da vida, ao acaso, à imprevisibilidade e também ao tempo dos acontecimentos incorporais.

Na perspetiva do ativista urbano PhilipYang (2017), desde a génese dos aglomerados urbanos, a organização das cidades resultou - ora mais ora menos - da ação e intervenção de três vetores de poder: económico (mercado), político (Governo, Estado) e social (sociedade). Seguindo ainda o pensamento de Yang, por consequência, poder-se-ia dizer que a ausência ou a dominação de algum destes vetores na produção do espaço urbano acabaria por produzir o desequilíbrio em alguma das dimensões da própria cidade - função, sustentabilidade, funcionamento, etc. - cujo efeito, em última instância, é sempre o próprio desestabilizar e enfraquecer do jogo democrático (cf. Yang, 2017).

Diante da possibilidade de estarmos a experienciar uma nova era geológica determinada pela ação antropológica na Natureza, configurada pelos interesses e agendas capitalistas em sua versão biopolítica - aqui no mais rigoroso sentido foucaultiano -, poder-se-ia dizer, também com Yang, que o direito à cidade institui, hoje, outras centralidades, expressas noutras necessidades, como a invenção de outras formas de vida para além de um humanismo neoliberal. E parece exigir-se também uma íntima e forte vinculação a uma outra categoria do Direito, hoje inédita e complementar: a do direito da natureza e das futuras gerações de seres humanos e não humanos. ${ }^{5}$

\footnotetext{
${ }^{5}$ Vale, neste aspeto, evocar o pensamento do filósofo alemão Hans Jonas que concebe uma outra e nova ética, que descentra a posição antropológica dominante até então. Jonas entende que é da responsabilidade ilimitada dos humanos: cuidar e manter a natureza e afiançar o bem-estar e a existência de futuras gerações. Enfim, caberia aos humanos preservar a vida na terra.
} 
O pensamento de Lefebvre, apesar de recusar o aviltamento da natureza e certa apropriação dela, pelo homem, na construção do espaço urbano - quando ela, natureza, é, por exemplo, reduzida ao valor de troca e à mercadoria, por interesses de uma sociedade de consumo (cf. Lefebvre, 2001) -, acaba por colocar, ainda, as necessidades humanas como dominantes e transcendentes. O que hoje parecemos descortinar, ainda em virtualidade, é a emergência da necessidade de tomarmos o problema do direito à cidade inscrito numa radical imanência e numa ética dos encontros. Neste sentido, vale a pena evocar a voz de Baruch Spinoza, filósofo do século XVII, no seu sentido de absoluta imanência, de radical dimensão ecológica:

"A maior parte daqueles que escrevem sobre (...) a maneira de viver dos homens parecem ter tratado, não de coisas naturais que seguem as leis comuns da Natureza, mas de coisas que estão fora da Natureza. Mais ainda, parecem conceber o homem na Natureza, como um império num império. Julgam [...] que o homem perturba a ordem da Natureza mais que a segue, que ele tem sobre os seus actos um poder absoluto e apenas tira de si mesmo a sua determinação" (...). (Spinoza, 1992 [1677], p. 263).

Dito de modo diferente: talvez, não seja exagero dizer que se a obra de Lefebvre avança, por um lado, focando-se na força social, portanto, na sociedade; por outro, acaba por tratar o problema da cidade pela dimensão transcendente dos próprios humanos. O que coloca, portanto, um paradoxo. Ou seja: avança quando pensa e aponta que o direito só será possível de realizar-se numa matriz outra, que não a capitalista. E que, portanto, o direito à cidade é o direito à liberdade, à individuação nos processos de socialização, à vida urbana e a tudo que esta puder fomentar; especialmente, a construção de local de encontros e de trocas, cujos usos serão determinados pela própria vida, mas, também, pelos empregos. Mas parece ser insuficiente quando não vislumbra, em última instância, a íntima e visceral articulação entre o direito à cidade e o direito da natureza e das gerações futuras de seres humanos e não humanos.

"Produzir um novo humanismo, diferente do velho liberal que está terminando sua existência: o humanismo do homem urbano para o qual e pelo qual a cidade e sua própria vida cotidiana se tornam obra, apropriação, valor de uso (e não de troca) servindo-se de todos os meios da ciência, da arte, da técnica, do domínio sobre a natureza material". (Lefebvre, 2001, p. 140, destaque das autoras)

Portanto, pôr em cena a questão do direito à cidade neste nosso tempo, com tantas restrições ao Direito, de modo efetivo, é lançar a construção de um outro e novo humanismo, onde se estabeleça definitivamente uma relação de composição e não uma relação transcendente, onde os humanos se sintam à parte da Natureza, "um império dentro de um império" (Spinoza, 1992 [1677], p. 263). 
Uma Ética da Responsabilidade Frente Às Diferenças, À Imprevisibilidade DA Vida E A UM TEMPo Por VIR

Frente ao cenário aqui configurado, parece irrefutável a necessidade da produção de um vertiginoso desvio ou deslocamento; qual seja, aquele que alcance o plano ético; mais precisamente, o da ética da responsabilidade.

Que sentido tem hoje a responsabilidade? Tornamo-nos aptos a devastarmonos? E ao planeta Terra? Somos conscientes dos efeitos de nossas ações? E das nossas omissões? E da nossa interferência na natureza junto aos outros seres, vivos ou não? Conseguimos uma relação de equilíbrio com os outros seres humanos que se constituem numa diferença, fora dos nossos padrões de consumo (cf. Giacóia Jr, 2017)?

Com o filósofo Giacóia, ao comentar a conferência de Peter Sloterdijk acerca de outras configurações da ideia de responsabilidade no mundo contemporâneo, poder-se-ia dizer que a responsabilidade social e a honestidade intelectual estão impostas, hoje, em proporção "direta à responsabilidade assumida tanto pelo saber que efetivamente temos, quanto pelo que não sabemos, mas temos condições de prognosticar e prever" (2017, s/p). E aqui abarcando, inclusive, os chamados prognósticos sombrios. E complementa: "a responsabilidade social diz respeito a cada um de nós - também aos intelectuais e não apenas aos técnicos (arquitecto, designer, cientistas, etc.) - (...) que habita uma sociedade que foi planetariamente unificada, mundialmente, pela ação do mercado e do desenvolvimento técnicocientífico" (Giacóia Jr, 2017, s/p).

E exatamente aí, quando põe em cena a questão de termos as condições da produção de prognósticos sombrios, Giacóia não deixa de desvelar um ponto de ressonância entre os pensamentos de Sloterdijk e Hans Jonas.

Hans Jonas foi um dos primeiros e mais notáveis pensadores a analisar, na contemporaneidade, a questão da responsabilidade pela vida como um princípio ético, enunciado principalmente na obra O Princípio Responsabilidade (1979) que, segundo o autor, necessitaria ser pensada a partir de um outro paradigma: por um lado, ao invés de uma ética do presente, fazer emergir uma outra dimensão de natureza ou qualidade diversa, desvelada por um sentido prospetivo, o de um mundo por vir. E, por outro, uma outra modalidade da relação homem-natureza não mais inscrita numa racionalidade instaurada em bases subjetivas, mas fundada na responsabilidade. Outra ética que, segundo Jonas, precisa imputar limites ao exercício, à prática da própria ciência e da tecnologia, agora, convertida o telos do homem contemporâneo - seja pela afirmação da noção de prudência, seja pela prospeção dos efeitos da qualidade sombria produzidos por ambas.

Portanto, hoje, ainda com Giacóia $(2001 ; 2013 ; 2017)$, as nossas éticas advindas da tradição são necessariamente desterritorializadas e postas em 
variação, uma vez que são todas antropocêntricas, seja numa perspetiva empirista tanto quanto racionalista. O homem, como algo exterior, tem ocupado o lugar de senhor da criação ao nomear a própria Natureza e, portanto, ao apropriar-se dela, como se não fosse uma parte dela. Numa perspetiva histórica, conforme o filósofo, a ética tem estado referida à polis e não à natureza, à physis, separando, pois, a cidade da natureza.

Em 1987, através da ONU, estabelece-se que o desenvolvimento precisa ser sustentável e não deve colocar em risco o sistema natural que sustenta a Vida na Terra. Eis o que preconiza o relatório Brundtland (Our Common Future) ${ }^{6}$. Um documento que exprime, em última instância, a emergência de uma outra e nova modalidade de pensar, um outro "paradigma". A transição de um paradigma mecanicista para outro, o da complexidade, que, de modo incontestável e urgente, considera a necessidade de transfigurarmos a nossa própria relação com a Natureza. Portanto, ainda com Giacóia (2017), lançando ao palco contemporâneo a urgente necessidade de uma vigilância permanente frente ao equilíbrio ecológico, que precisa ser reconhecido não apenas em relação à geração atual como às gerações que ainda estão por vir - sejam os humanos ou não humanos.

Exatamente na perspetiva deste problema é que interessa a este trabalho operar um segundo desvio ou deslocamento para alcançar uma outra dimensão da ética da responsabilidade, qual seja, a necessidade inadiável de um equilíbrio ecológico, com vistas a enfrentar a desterritorialização-reterritorialização de nosso modo de civilizar, nos dias atuais: uma relação radicalmente outra entre natureza e cidade, onde as diferenças e as singularidades constitutivas da vida, o acaso, a imprevisibilidade e também o tempo dos acontecimentos incorporais possam ser afirmados e potencializados ao serviço da criação da existência ativa.

\section{A Busca por uma Composição, Radicalmente Outra, entre Natureza e Cidade}

A própria ideia de composição já sugere uma aproximação entre os conceitos de Direito à Cidade e de Antropoceno, em seus determinantes não apenas económicos; mas, sobretudo, históricos, sociais e políticos: a aguda e urgente necessidade de uma relação, radicalmente outra, entre natureza e cidade, agora num território esgaçado num mundo global. Relação onde a escalada da ação humana, sobre a natureza e as cidades, produtora de violência, desigualdades desproporcionais, diferenças e hierarquias, segregação social e espacial, fragmentação, periferização, ausência de direitos (cf. Carlos, 2020); enfim, crises jamais vistas. Ação humana refém de forças configuradas num hibridismo: por um lado, a necessidade, no plano da vida e

\footnotetext{
${ }^{6}$ Disponível na biblioteca digital da ONU: https://digitallibrary.un.org/record/139811
} 
no quotidiano, da reprodução das relações de produção indispensáveis à manutenção do capitalismo. E, por outro, o extraordinário domínio da ciência e da técnica a avançar no domínio da natureza, da vida.

É, pois, diante deste panorama, em especial, pela voz dos movimentos sociais, que o século XXI multiplica a profunda e urgente necessidade de uma grande política, no mais rigoroso sentido nietzscheano: a afirmação do direito à cidade -aqui destituída de qualquer vestígio de redução ao plano físico- e confronto com o antropoceno, cujo primeiro estágio é, hoje, reconhecido na pandemia global que experienciamos.

Nas entranhas de nossas cidades globais um novo se anuncia e emerge: uma pandemia a alcançar um espaço planetário. Ou seja: a força do insólito e do imprevisível, hoje, significando, impelindo a reordenação de todo o acontecido passado. E como nos mostra o físico Luiz Alberto Oliveira, curador do Museu do Amanhã, uma pandemia que, em última instância, é antropoceno funcionando como um índice de nosso estágio civilizatório (cf. Oliveira, L.A \& Rolnik, 2020).

Embora seja notório que Lefebvre tenha sido afetado por dois expressivos pensadores ocidentais e suas obras, nomeadamente Hegel e Marx, aqui, na finalização deste texto, interessa-nos convocar uma terceira - não menos expressiva e decisiva no resultado da obra de Henri Lefebvre: a do filósofo alemão Friedrich Nietzsche. Afeção, cujos afetos se exprimem na própria produção de Lefebvre, quando ele próprio, por exemplo, em sua autobiografia, La Somme et le reste, de 1959, problematiza a sua forte implicação com a filosofia de Nietzsche, na década de 1930. Ou mesmo na sua obra Hegel, Marx, Nietzsche ou o reino das sombras, de 1976.

Ainda que reconheçamos a pluralidade da proximidade de Lefebvre com o pensamento nietzscheano, aqui, num foco de aproximação máxima, impõe-se destacar um aspecto específico, de uma utopia imanente - a de um certo humanismo, ideia que atravessa as suas obras:

"A ideia de um humanismo nietzscheano diz respeito à tentativa presente em suas obras de resgatar uma série de elementos que marcaram o alvorecer e o esplendor da cultura europeia e ocidental - os impulsos apolínios e dionisíacos, o sentido do trágico, a centralidade da arte, entre outros. Nietzsche 'imaginou a restituição desses elementos de um humanismo renovado' e 'a cultura europeia, reintegrando seus elementos dispersos, degradados pelo cristianismo' (Lefebvre, 2008 [1959], p. 460). Para isso, montou um ataque à figura do homem teórico, ao socratismo científico e otimista e ao ideal ascético que iria predominar sobre as formas de conhecimento e de vida, postulando uma crítica transvalorativa dos valores morais que dominaram a prática social e a constituição de uma cultura que fosse capaz de reunificar seu estilo e suas obras de arte em torno da afirmação da vida" (Fernandes, 2021, p. 261). 
Comecemos pela potência da literatura em operar a grande política, tão cara ao pensamento nietzscheano. Trata-se de fragmento do texto "O fim de uma era. A cidade mais privilegiada da Itália está na fila do pão", de Antonio Scurati (2020), que aí vive e, que, sob o impacto do incómodo isolamento social, faz extrair sentidos das cenas insólitas, agudamente impressionantes e angustiantes que vê de sua janela:

"Como posso convencer a minha mulher de que, enquanto olho pela janela, estou a trabalhar - perguntava-se Joseph Conrad no início do século passado. Eu, em vez disso, pergunto-me: como posso explicar à minha filha que, quando olho pela janela, vejo o fim de uma era? A era em que ela nasceu, mas que não conhecerá, a era do mais longo e distraído período de paz e prosperidade desfrutado na história da humanidade (...) Vivo em Milão, até ontem a mais evoluída, rica e brilhante cidade de Itália, uma das mais desejadas do mundo. A cidade do aperitivo, que deu ao mundo Negroni Sbagliato e a happy hour (...)

E que hoje é a capital mundial do Covid-19, a capital da região que, sozinha, soma trinta mil contágios confirmados e três mil mortos. Uma taxa de mortalidade de $10 \%$ (...) os caixões empilhados à frente dos pavilhões dos hospitais, uma pestilência vaporosa que paira sobre as torres da sua catedral como sobre as cidades amaldiçoadas das antigas tragédias gregas. As sirenes das ambulâncias tornaram-se a banda sonora dos nossos dias; as nossas noites são atormentadas" (...)

Milhares de amigos, parentes e conhecidos tossem até cuspir sangue, sozinhos, fora de todas as estatísticas e sem qualquer assistências, na cama de seus estúdios decorados por arquitetos de renomes (...)

São homens e mulheres adultos, contudo por cima das máscaras mostram o olhar assustado das crianças carentes. Chegaram totalmente despreparados ao seu encontro com a história e, no entanto, precisamente por esse motivo, são homens e mulheres corajosos. Viveram bem, melhor do que qualquer outra pessoa, mas quanto mais viviam, mais inexperientes eram na vida: nunca conheceram o terror da guerra, nunca foram tocados pelo sentimento trágico da existência". (s/p)

Há muito as transformações do tempo histórico que experimentamos, nas suas macro e micro realidades, impõem um profundo e inadiável confronto com o mundo ocidental, que, na senda do pensamento nietzscheano - mas também do filósofo contemporâneo Gilles Deleuze, poder-se-ia dizer, refere-se precisamente à

\footnotetext{
7 "O fim de uma era. A cidade mais privilegiada da Itália está na fila do pão" de Antonio Scurati (2020) consta da Coleção "Janelas para o Mundo", organizada pelo jornal alemão Frankfurter Allgemeine Zeitung, onde vários escritores e filósofos de todo o mundo escrevem sobre o que veem das suas janelas durante o período de isolamento motivado pela pandemia da Covid-19. Como sinal de proximidade cultural em tempos de distância política e social, artigos desta coleção são publicados também noutros jornais internacionais, como o Corriere della Sera (Itália), o Politiken (Dinamarca), o Observador (Portugal) e o Die Presse (Áustria).
} 
dimensão do pensamento - desde que aqui fique claro que pensamento, no sentido ora afirmado, não se dissocia ou mesmo não se sobrepõe ao corpo. Ou seja: é absolutamente necessário que pensemos diferente; inventemos outros modos de pensar, diferentes do que criamos até então, com a ideia de que a transcendência e soberania da razão constituir-se-iam na "chave dos grandes problemas" do ocidente. Um outro pensar onde os afetos, o corpo, os ritmos da vida, as diferenças e as singularidades constitutivas da vida, o acaso, a imprevisibilidade e também o tempo dos acontecimentos incorporais possam ser afirmados e potencializados a serviço da criação intensiva e ativa da existência. Aguda necessidade já anunciada por Nietzsche e revisitada por Michel Foucault, em sua obra o Uso dos Prazeres, datada de 1984:

"De que valeria a obstinação do saber se ele assegurasse apenas a aquisição dos conhecimentos e não, de certa maneira, e tanto quanto possível, o descaminho daquele que conhece? Existem momentos na vida onde a questão de saber se se pode pensar diferentemente do que se pensa, e perceber diferentemente do que se vê, é indispensável para continuar a olhar ou a refletir". (p. 13)

Importa, assim, aproximar a fórmula foucaultiana à nietzscheana, a da transvaloração de todos os valores (cf. Nietzsche, 1999). Um pensar diferente só é alcançado se - e somente se - formos capazes, de maneira simultânea, operar uma outra produção, a partir de nossos processos sociais e culturais e de subjetivação: a transvaloração de nossos valores capitalistas, neoliberais, que, de modo cínico, inscreve uma enganosa dicotomia entre vida e negócios-capital, com uma suprema valorização do Capital.

Experimentamos o fim de uma era? Tratar-se-ia do primeiro estágio do estado de coisas chamado de Antropoceno? Ou seja: o Coronaceno? A pandemia de COVID-19, que alcançou todos os continentes - hoje, exceto a Antártida -, que faz emergir uma crise globalizada, jamais vista em tempo algum, insinua-se como um potente signo a violentamente abalroar os nossos corpos, nossos pensamentos, tomados, aqui, forçosamente como um acontecimento; a um só tempo, levando-os a um não saber e, por consequência, a criar, a instá-lo a ser decifrado em múltiplos e diversos sentidos.

Mas, apesar de seus devastadores efeitos, trata-se de um desastre já anunciado por algumas vozes das ciências; mas, também, dos próprios negócioscapital. ${ }^{8}$ Não foram ouvidas? Ou não se quis ouvi-las em razão do inebriamento e do torpor fabricado pelo Capital, que capturam os nossos sentidos? Como se

\footnotetext{
${ }^{8}$ No âmbito da ciência, o professor e investigador Carlos Afonso Nobre, cientista sénior do Instituto Nacional de Pesquisas da Amazônia (INPA-Brasil). No âmbito de negócios-capital, o próprio Bill Gates.
} 
compreende nenhuma mobilização dos gestores de nossas muitas cidades, em escala mundial, para poupar vidas, antes da pandemia se tornar uma realidade atualíssima? Desdém das próprias ciências ao conceberem as suas políticas públicas? Sensibilidades e subjetividades solapadas, cristalizadas, capturadas, incapazes de apreender as realidades fugazes, o acaso, a imprevisibilidade e também o tempo dos acontecimentos incorporais?

Uma era desterritorializa-se, de modo brusco... e vai reterritorializandose, num outro ritmo, numa duração... Mas, necessariamente, esse abalo, e seu consequente desarranjo, trazem também, em si, de modo paradoxal, o desafio e a força para a abertura de outros mundos possíveis - e por que não, impossíveis, a partir da criação do próprio real e da invenção de outros valores e de novos modos de existir.

No entanto, neste momento, mais uma vez, outras vozes minoritárias tornam-se audíveis; por exemplo, a do cientista brasileiro Carlos Nobre (2018) aqui minoritário necessariamente no sentido deleuziano. E já anunciam que esta pandemia global deixa entrever que o pior ainda pode estar por vir e que esse pior diz respeito à negligência face a uma outra e absoluta necessidade global, denegada por muitas das nossas lideranças políticas, em todo mundo, especialmente as de países ricos: enfrentar e ultrapassar a trepidante relação entre Natureza e Cidades, que vimos construindo. Eis o atual e agudo desafio da cultura ocidental: a construção de uma composição, uma relação, radicalmente outra, entre Natureza e Cidades. Tomar a desterritorialização civilizatória que experimentamos, onde valores são tornados insuficientes para criar outros modos de viver, em aguda composição com a Vida necessária, potente e criativa, e outros modos de pensar - especialmente apartados de uma "imagem dogmática do pensamento", de categorias como "verdade-juízo", "transmissão e aquisição", "certeza e tempo linear”, "dicotomia e analogia", "sujeito e objeto", "consciência e representação", "bem e mal", "livre-arbítrio", psicológico e social, etc. Outras maneiras de experimentar, a um só tempo, o “corpo-espírito", o "desejar e o subjetivar"; a própria criação do real. Eis o fora de nós e o novo que se impõe urgentemente a ser construído num tempo por vir. Uma necessidade de transvaloração e de invenção de outras modalidades de operar a sensibilidade, o pensar, de criar nossos próprios problemas, inscritas, agora, num pensamento sem imagem, destituídas de qualquer vestígio de erudição, distanciamento e neutralidade (cf. Deleuze, 2018) frente à própria cultura na qual se inscreve e escreve.

Tempo de travessia... que nos impõe, com sofisticada crueldade, que nos façamos no encontro com outras realidades de dimensões, qualidades e intensidades diferenciadas e que nos libertemos do insidioso valor que repudia a zona de indeterminação que inscreve e povoa a própria vida. Modos de ser singulares a experimentar o plano comum entre humanos e natureza. Travessia desafiante e 
absolutamente necessária para nos levar a outros lugares... a outros modos de ocupar e produzir os espaços, a outras subjetividades, outras produções e práticas sociais e de outras riquezas, para além do dinheiro... outros tempos, outros humanismos, inéditos... Mas sempre metaestáveis!

Há um tempo em que é preciso

Abandonar as roupas usadas

Que já tem a forma do nosso corpo

E esquecer os nossos caminhos que nos levam sempre aos mesmos lugares

É o tempo da travessia

E se não ousarmos fazê-la,

Teremos ficado para sempre

À margem de nós mesmos (...). (Andrade, 2015, s/p.) ${ }^{9}$

\section{BIBLIOGRAFÍA}

Andrade, F. T. (2015, setembro 7). “O Tempo da Travessia” [online]. In "Tempo de Travessia poema de Fernando Teixeira de Andrade; das polêmicas em relação ao crédito; um pouco sobre o professor". aulas \& memórias \& práticas \& leituras prof.Gilberto. Acedido a 10 de abril de 2020. https://aulasprofgilberto.blogspot.com/2015/09/tempo-de-travessia-poema-de-fernando.html.

Carlos, A. F. A. (2020). Henri Lefebvre: o espaço, a cidade e o "direito à cidade" [online]. Dossiê, Rev. Direito e Práxis, 11(01), Jan-Mar. Acedido a 15 de maio de 2021. https://doi. org/10.1590/2179-8966/2020/48199

Carlos, A. F. A. (2020b, n.d.). A Atualidade de Henri Lefebvre [vídeo]. Conferência Editora Consequência. Acedido a 10 de maio de 2021. https://www.youtube.com/ watch? $\mathrm{v}=\mathrm{J} 81 \mathrm{~d} X \mathrm{X} \ln O \mathrm{~d} 4 \& \mathrm{t}=210 \mathrm{~s}$

Deleuze, G. (1976). Nietzsche e a Filosofia. Rio de Janeiro: Ed. Rio.

Deleuze, G. (2018). Diferença e Repetição. São Paulo: Paz \&Terra.

Fernandes, B.S. (2021). A Influência da Filosofia de Friedrich Nietzsche na obra de Henri Lefebvre: da crítica da vida cotidiana à teoria da produção do espaço [Dissertação de Mestrado não publicada]. Instituto de Geociências, Faculdade de Geografia da Universidade Federal de Minas Gerais, Brasil.

Foucault, M. (1984). O Uso dos Prazeres, V.II. São Paulo: Ed. Paz e Terra.

Giacóia, Jr., O (2001). Nietzsche como Psicólogo. Porto Alegre: UNISINOS.

Giacóia, Jr. (2013). Nietzsche: O Humano como Memória e como Promessa. Petrópolis: Ed. Vozes.

${ }^{9}$ Este texto, muitas vezes, é atribuído a Fernando Pessoa; mas, em realidade, é de Fernando Teixeira Andrade. 
Giacóia, Jr. (2017, outubro 30). A Ética da Responsabilidade [vídeo]. Café Filosófico, CPFL/ TV Cultura- SP. Acedido a 10 de outubro de 2019: https://www.youtube.com/ watch? $\mathrm{v}=$ nJm2nofC0Us\&t $=553$

Jonas, H. (2006 [1979]). O Princípio Responsabilidade: ensaio de uma ética para a civilização tecnológica. Rio de Janeiro: Editora Contraponto.

Lefebvre, H. (1968). Le droit à la ville. Paris : Antropos.

Lefebvre, H. (1976). Hegel, Marx, Nietzsche ou O reino das sombras. Póvoa de Varzim: Editora Ulisseia.

Lefebvre, H. (2001). O Direito à Cidade. São Paulo: Centauro.

Lefebvre, H. (2001b). La fin de l'histoire. Paris: Antropos/ Económica.

Lefebvre, H. (2008 [1959]). La Somme et le reste. Paris: Economica-Anthropos.

Lefebvre, H. (2008b [1970]). A revolução urbana. Belo Horizonte: EdUFMG.

Nietzsche, F. (1999). Genealogia da Moral. São Paulo: Cia das Letras.

Nobre, C. (2018). Sistema Terra: uma forma integrada de estudar as mudanças ambientais e suas consequências [online]. Entrevistado pelo Profo José Eli da Veiga. Instituto de Estudos Avançados - USP/IEA-Brasil. Acedido a 10 de dezembro de 2020. http://www.iea.usp.br/ noticias/sistema-terra

Oliveira, L.A. \& Rolnik, S. (2020, n.d.). Encontros AULAS ABERTAS - Arte e Ciência em quarentena [vídeo]. Casa do Saber. Acedido a 15 de dezembro de 2020. https://www.

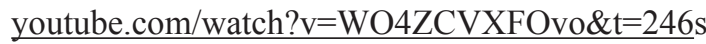

Oliveira, S. B. (2018, abril 26). Conversa sobre Antropoceno [vídeo]. Instituto de Estudos Avançados da USP/IEA - Brasil. Acedido a 5 de julho de 2019. https://www.youtube.com/ watch?v=pqd1vjZWH98

Pereira, C. S. S. (2018). "Mudar a Vida": da Revolução Urbana à Revolução do Espaço - O Projeto de Henri Lefebvre. GEOgraphia, 20(43), 21-35. https://doi.org/10.22409/ GEOgraphia2018.v20i43.a27209

Safatle, W. (2019, setembro 16). Presente, Pós-verdade e Experiência de Passado [vídeo]. Ciclo de Conferências Memória e Patrimônio, SESC/SP. Acedido a 10 de maio de 2021. https: //www.youtube.com/watch? $v=E 9 G W v$ ymJe $Q \& t=1569 \mathrm{~s}$

Scurati, A. (2020, março 25). O fim de uma era. A cidade mais privilegiada da Itália está na fila do pão [online]. Coleção "Janelas para o Mundo", org. Frankfurter Allgemeine Zeitung. Acedido a 12 de abril de 2020: https://observador.pt/especiais/milao-a-cidademais-privilegiada-de-italia-esta-agora-na-fila-do-pao/

Sloterdijk, P. (2016). Sobre a fúria dos titãs no seculo XX. São Paulo: Fronteiras do Pensamento.

Souza, L. (2019, fevereiro 12). Sobre Henri Lefebvre [vídeo]. 1\# Irene no Mar. Acedido a 12 de maio de 2021. https://www.youtube.com/watch? $\mathrm{v}=$ Tn_OhLQtxf8\& $\mathrm{t}=22 \mathrm{~s}$

Spinoza, B. (1992 [1677]). Ética. Lisboa: Relógio D’Água Editores.

Yang, P. (2017, n.d.). Cidades Possíveis: construção colectiva [vídeo]. Café Filosófico, CPFL/ TV Cultura SP. Acedido a 5 de outubro de 2019. https://www.youtube.com/ watch?v=7Vo-YYns5c 